\title{
Regional prevalence and determinants of exclusive breastfeeding in India
}

\author{
Felix Akpojene Ogbo ${ }^{1,2^{*}}$ (D, Mansi Vijaybhai Dhami ${ }^{1}$, Akorede O. Awosemo ${ }^{2}$, Bolajoko O. Olusanya ${ }^{3}$, \\ Jacob Olusanya ${ }^{3}$, Uchechukwu L. Osuagwu $^{4}$, Pramesh Raj Ghimire ${ }^{5}$, Andrew Page ${ }^{1}$ and Kingsley E. Agho ${ }^{5}$
}

\begin{abstract}
Background: Exclusive breastfeeding (EBF) has important benefits for both the mother and child. In India, no nationwide studies have examined patterns of EBF in the past decade to inform national and subnational breastfeeding programmes. The present study aimed to investigate the regional prevalence and determinants of EBF in India.

Methods: This study used a total weighted sample of 21,352 from the 2015-2016 India National Family Health Survey. EBF was measured as the proportion of infants $0-5$ months of age who received breast milk as the only source of nourishment, based on mother's recall on feeds given to the infant $24 \mathrm{~h}$ before the survey. The prevalence of EBF and other breastfeeding patterns were estimated by region, and multivariable logistic regression that adjusted for clustering and sampling weights was used to investigate the association between the study factors (child, maternal, household, health service and community factors) and EBF by regional areas in India.

Results: This study indicated that wide differences in the prevalence of EBF and other childhood feeding practices exist across regions of India, where Southern India had the highest EBF prevalence (79.2\%) and the North-East reported the lowest (68.0\%). EBF prevalence decreased with infant age, dropping faster in the South (43.7\% at 5 months) compared to the North-East region (54.0\% at 5 months). Similarly, substantial variations in key determinants of EBF were evident by region, where higher birth order was the only common factor associated with non-EBF across all regions. Key modifiable determinants of non-EBF included higher maternal education in the South and belonging to rich households in Central India, while those for EBF were higher maternal education in the Central region and frequent antenatal care $(\geq 4)$ visits in Northern India.

Conclusion: This study demonstrates wide variations in regional prevalence and determinants of EBF in India. Improving EBF participation in India would require multifaceted national and subnational efforts that include dedicated funds and the establishment of appropriate policy and interventions that are consistently monitored and evaluated.
\end{abstract}

Keywords: Exclusive breastfeeding, Infants, India, Region, Nutrition

\section{Background}

The first 1000 days (between conception and a child's second birthday) provides a unique period of opportunity for optimum child growth and development and also establishes the foundations for good health across the life course [1]. During this period, appropriate infant and young child feeding practices (IYCF) are critical for the child's health

\footnotetext{
* Correspondence: felgbo@yahoo.co.uk; f.ogbo@westernsydney.edu.au

${ }^{1}$ Translational Health Research Institute (THRI), School of Medicine, Western Sydney University, Campbelltown Campus, Locked Bag 1797, Penrith, NSW 2571, Australia

${ }^{2}$ Prescot Specialist Medical Centre, Welfare Quarters, Makurdi, Benue State, Nigeria

Full list of author information is available at the end of the article
}

and well-being [2-4]. Essential components of IYCF practices include timely initiation of breastfeeding, exclusive breastfeeding (EBF) for the first 6 months of life and continued breastfeeding until the child is 2 years of age, including the timely introduction of appropriate complementary foods [5]. EBF (defined as the practice of only giving an infant breast milk for the first 6 months of life, with no other food or water added) is the cornerstone of optimum infant nutrition [5]. Notably, EBF reduces the risk of the infant to experience diarrhoeal diseases $[2-4,6]$, upper respiratory tract infections, obesity in later life, and EBF could improve the neurocognitive functions of the child [4].

(C) The Author(s). 2019 Open Access This article is distributed under the terms of the Creative Commons Attribution 4.0 International License (http://creativecommons.org/licenses/by/4.0/), which permits unrestricted use, distribution, and reproduction in any medium, provided you give appropriate credit to the original author(s) and the source, provide a link to the Creative Commons license, and indicate if changes were made. The Creative Commons Public Domain Dedication waiver (http://creativecommons.org/publicdomain/zero/1.0/) applies to the data made available in this article, unless otherwise stated. 
Globally, India has the highest under-five mortality (0.9 million deaths in 2016) [7], attributable to an array of factors such as poverty, poor water and sanitation, poor healthcare access and non-EBF [8, 9]. Between 2005 and 2016, past national studies from India reported an improvement in EBF prevalence by $9.0 \%$ (from 46.0 to $55.0 \%$ ) [10]. However, national data often mask significant variations across the regions. For example, findings from discrete sub-national studies have shown that EBF varied widely in India, ranging from $36.0 \%$ in Meghalaya to $77.0 \%$ in Chhattisgarh [11]. Similarly, studies from informal settlements have also reported broader and lower findings, between $11.4 \%$ [12] and 63.0\% [13].

A national study based on the analysis of the 1992 and 2006 India Demographic and Health Surveys (DHS) indicated that the differences in EBF prevalence may be due to the impact of sociodemographic (higher maternal education, low household wealth status and older maternal age, $\geq 35$ years), health service ( $\geq 4$ antenatal care visits) and community (urban residence) factors [14]. However, it is unclear whether these key factors have changed in the past decade given the economic and social mobility of women [15], as well as gender role differentiation in India $[16,17]$. Additionally, findings from the 2015-16 India DHS - the data source for the present study - may not be comparable to previous national surveys because of differences in the sample size. In the 2006 India DHS, approximately 110,000 households were sampled from 1028 million people using the 2001 census frame [18] compared to the 2015-16 DHS, where approximately 572,000 households were sampled from 1210.2 million people based on the 2011 census frame. More importantly, the 2015-16 DHS methodology has been recognised as the standard for future national surveys [18], suggesting the need for baseline and up-to-date evidence on EBF to guide national and subnational policy interventions in India.

Furthermore, a detailed understanding of the regional prevalence along with the determinants of EBF is essential for decision-makers to provide locally relevant policies and resources, and for public health administrators to design targeted interventions to improve EBF in India. This study aimed to examine the prevalence and determinants of EBF in India. We also took advantage of the comprehensiveness of the data and will report on the prevalence of other breastfeeding practices (i.e., the provision of breast milk plus water, juice, milk and other liquids to children) in the context of EBF by regional areas in India.

\section{Methods}

\section{Data sources}

The study used data from the 2015-16 India DHS, also known as the National Family Health Survey (NFHS-4). The data were collected by the International Institute for
Population Sciences (IIPS), supervised by the Ministry of Health and Family Welfare (MoHFW), Government of India, and technical assistance provided by Inner City Fund (ICF) International, Maryland, USA. Information relating to infant and young child feeding practices (including EBF), as well as socioeconomic characteristics, was collected from a nationally representative sample of women aged 15-49 years from 572,000 households. The total sample was obtained in a two-stage sampling design for both rural and urban areas in the country, with villages and census enumeration blocks as the primary sampling units (PSU), respectively. In the selected rural and urban PSU, approximately 300 households were selected and were further divided into segments of about 100-150 households. Two of these segments were randomly selected for the NFHS-4 using systematic sampling with probability proportional to segment size. Thus, an NFHS-4 cluster is either a PSU or a segment of a PSU. In the second stage of the sampling, 22 households were randomly selected from every selected rural and urban cluster using a systematic sampling method [18].

To obtain the sample of mothers who exclusively breastfed in the first six months of birth, as well as reduce the potential effect of recall bias [19], we restricted our analyses to the youngest living children aged 0-5 months, living with respondents (women aged 15-49 years). The total weighted sample was 21,352 maternal EBF responses. Similarly, in the assessment of other infant and young child feeding practices, the analyses were restricted to the specific age groups for those indicators, consistent with the World Health Organization (WHO) and United Nations Children's Funds (UNICEF) definitions [5]. The survey had high response rates that varied between Indian states and territories, from 94.0\% in Andhra Pradesh and West Bengal [20, 21] to $99.6 \%$ in Bihar [22]. Additional information on the survey methodology is provided in the final India DHS reports [18, 20, 22].

India is a federal union that comprises 29 states and 7 union territories - a total of 36 jurisdictional entities. The states and union territories are aggregated into six zonal councils to facilitate better economic integration, resource allocation and inter-state cooperation [23, 24]. In the present study, we used the six zonal regions, which include North, South, East, West, Central and North-Eastern India. The Northern region ( $n=2731$ maternal EBF responses) consists of the states of Jammu and Kashmir, Himachal Pradesh, Haryana, Delhi, Chandigarh, Punjab and Rajasthan. The Southern region $(n=3641)$ consists of the states of Andhra Pradesh, Karnataka, Kerala, Tamil Nadu, Telangana, Andaman and Nicobar Islands, Lakshadweep Islands and the Union Territory of Puducherry. The Eastern region $(n=5177)$ consists of Bihar, Jharkhand, Odisha and West Bengal. The Western region $(n=2572)$ consists of the states of Gujarat, Maharashtra, Goa, Daman and Diu 
as well as Dadra and Nagar Haveli. The Central region $(n=6425)$ consists of the states of Chhattisgarh, Madhya Pradesh, Uttar Pradesh and Uttarakhand. The North-Eastern region $(n=806)$ consists of the states of Arunachal Pradesh, Assam, Manipur, Meghalaya, Mizoram, Nagaland, Sikkim and Tripura.

\section{Outcome variable}

EBF was measured as the proportion of infants $0-5$ months of age who received breast milk as the only source of nourishment (but who also received oral rehydration solution, drops or syrups of vitamins and medicines). This indicator was based on mother's recall on feeds given to the infant in the last $24 \mathrm{~h}$ before the survey. This was consistent with the WHO/UNICEF definitions for assessing IYCF practices [5]. The WHO/UNICEF recommend the use of the indicator, 'predominant breastfeeding', to measure infants $0-5$ months of age who received breast milk as the main source of nourishment, but allows water, water-based drinks, fruit juice, oral rehydration solution, drops, or syrups of vitamins and medicines.

\section{Study factors}

The study factors selected were based on evidence from previous studies [14, 25, 26]. The study factors included child, maternal, household, health service and community factors. Child factors included sex of the baby, child age, birth order, the perceived size of the baby and preceding birth interval. Maternal characteristics included the mother's highest educational level, employment status, marital status, literacy level, religion, age and type of caste or tribe. In the DHS, a mother was classified as literate if she had completed education to standard six or higher, or was able to read a sentence or any part of the sentence from a given literacy card. A detailed description of other study factors is provided in the NFHS-4 report [18].

Household/family characteristics included the frequency of listening to the radio, the frequency of watching television and frequency of reading newspaper, and household wealth index. The household wealth index was derived from a principal components analysis conducted by the IIPS and ICF International and was calculated as a score of ownership of household assets such as transportation device, ownership of durable goods and household facilities. The IIPS and ICF International classified the household wealth index into five categories (quintiles), and each household was assigned to one of these wealth index categories namely: poorest, poorer, middle, rich and richest. These data were re-categorised, where the bottom $40 \%$ of households represent poor households, the next $40 \%$ as the middle households and the top 20\% as rich households to ensure adequate sample in each category $[25,26]$. Health service factors included the number of antenatal clinic visits, the place of delivery, the mode of delivery, the timing of postnatal visits and the type of delivery assistance, while one community level factor included was a place of residence.

\section{Statistical analysis}

Initial analysis involved the estimation of frequencies and cross-tabulations to estimate the prevalence of EBF practice by region for all study factors examined. An estimation of the prevalence of EBF and other breastfeeding patterns with child age by regions was also conducted. This was followed by univariable and multivariable logistic regression generalized linear latent and mixed models (GLLAMM) with a logit link and binomial family that adjusted for clustering and sampling weights and was used to estimate the association between the study factors (child, maternal, household, health service and community factors) and EBF for each region in India.

In the multivariable analyses, a five-stage model was performed. In the first stage model, child characteristics were entered into the model and a manual stepwise elimination method was used to remove the non-significant factors $(p>0.05)$. In the second stage model, the significant factors in the first stage model were added to the maternal characteristics and this was followed by another manual stepwise elimination procedure which retained all the significant factors. A similar procedure was employed for the third and fourth stages, which included the household characteristics, as well as health services characteristics and the final stage model introduced the community factors. After completion of all five modelling stages, the factors that were significantly associated with EBF were retained.

We calculated and reported unadjusted odds ratios (Additional file 1) and statistically significant adjusted odds ratios (aORs) and their corresponding 95\% confidence intervals as the measure of association between the study factors and EBF in each Indian region. The analyses were performed in Stata version 14.0 (Stata Corp, College Station, Texas, USA).

\section{Ethics}

The DHS project sought and obtained the required ethical approvals from the Ethics Review Board of the International Institute for Population Sciences, Mumbai, India before the surveys were conducted, with informed consent obtained from participants during the surveys. Approval was sought from Measure DHS and permission was granted for this use.

\section{Results}

\section{Characteristics of the study participants}

Overall, the proportions of male and female children across six regions were similarly distributed, $52.8 \%$ vs $47.2 \%$ in North, $51.7 \%$ vs $48.4 \%$ in South, $52.9 \%$ vs $47.1 \%$ in East, $50.2 \%$ vs $49.8 \%$ in West, $51.4 \%$ vs $48.6 \%$ in Central, 
and $49.5 \%$ vs $50.6 \%$ in North-Eastern region. The prevalence of mothers who had no formal education was highest in the Eastern region (36.1\%) compared to their Southern Indian counterparts $(9.8 \%)$ [Table 1$]$.

\section{Regional distribution of EBF and other breastfeeding (BF) practices}

As shown in Fig. 1, the prevalence of EBF among infants aged $0-5$ months varied across the regions of India. EBF prevalence in infants aged 0-5 months was highest in the South $(79.2 \%)$ and lowest in the North-Eastern region (68.0\%). The EBF prevalence decreases as the infant grew older in the South $(75.8 \%$ at 1 month of age, $63.6 \%$ at 3 months of age and $43.7 \%$ at 5 months) compared to the North-East region $(70.0 \%$ at 1 month of age, $64.2 \%$ at 3 months and $54.0 \%$ at 5 months). Similarly, the proportion of children who received breast milk plus water, or breast milk plus water-based liquid or juice, breast milk plus other milk, or breast milk plus complementary foods from birth to 23 months of age varied substantially across Indian regions [Fig. 1].

\section{Regional determinants of exclusive breastfeeding}

Across all regions, children in the 2nd-4th and five or more birth order categories (in the North, Central, and North-East region) were less likely to be exclusively breastfed compared to first-born children (Table 2). Mothers with secondary and higher level of education were less likely to exclusively breastfeed their infants compared to those with no education in Southern India. In contrast, mothers with a similar level of education were more likely to exclusively breastfeed their infants compared to those with no education in Central India.

Lower EBF practice was observed among mothers with Christian and another religious background in Eastern India and among mothers of Muslim background in Central region. Mothers who belonged to the 'Scheduled tribe' had higher odds of practising EBF in East and North-East regions of India. In contrast, mothers from 'Other backward classes' in the East region were less likely to practice EBF (Table 2). In Southern India, children were less likely to be exclusively breastfed if they were female and were perceived to be born large compared to being male and those perceived to be small. In North-East India, EBF practice was significantly lower among mothers who were formerly married and higher among mothers whose infants were born via caesarean section compared to currently married mothers and those whose infants were born vaginally (Table 2 ).

In North India, infants born to mothers who had four or more antenatal visits were more likely to be exclusively breastfed compared to those whose mothers had no antenatal visit. Infants whose mothers resided in rural areas of Western India were less likely to be exclusively breastfed compared to their counterparts in urban areas. In Central India, children born to mothers from rich households were less likely to be exclusively breastfed compared to mothers who were from poor households (Table 2).

\section{Discussion}

Our study showed that substantial variations exist for the prevalence of EBF and other childhood feeding practices across the regions of India, demonstrating the socioeconomic, religious, cultural and geographical diversity in the country. Mothers who resided in Southern India had the highest EBF prevalence, while those in the North-East had the lowest prevalence. EBF prevalence decreased with infant age, declining faster in the South $(43.7 \%$ at 5 months) compared to the North-East region (54.0\% at 5 months). Similarly, this study found that the factors associated with EBF also varied widely across regional lines, where higher birth order was the only common factor associated with non-EBF in all regions of India.

In India, an estimated 0.9 million under-five deaths were reported in 2016 [7]. Of those deaths, approximately 50\% occurred in the neonatal period, a time when EBF has been shown to significantly improve child survival [27]. Our study indicated that EBF prevalence was lowest in the North-Eastern region, while in all regions, EBF prevalence decreased with the infant age, with the prevalence falling below $50 \%$ around the age of five months. These suboptimal EBF figures could be attributed to inadequate healthcare financing, planning and strategic actions on infant feeding [28]. At the community level in India, common traditional infant feeding practices associated with the early introduction of water and other water-based fluids before six months of age have also hindered interventions to promote EBF $[29,30]$. The establishment of national and subnational policy, programme and coordination for IYCF practices, as well as allocating special funds for implementation of those interventions remain key strategies for increasing India's EBF [28].

The present study showed that children of higher birth order (2nd or more) were less likely to be exclusively breastfed compared to first-born children in all regions. This result is inconsistent with evidence from Nigeria [26, 31], Tanzania [32] and regional areas of Sri Lanka [33] which found no association between the birth order of the child and EBF. In the Sri Lankan study, however, second born babies had a higher EBF rate compared to first-born babies, and the rate dropped further from the third baby [33]. In comparison to countries (such as Sri Lanka and Tanzania) with established national and subnational policy, programme and coordination for IYCF practices [34, 35], India's national and subnational IYCF strategy, as well as breastfeeding training for front-line health workers and support for new mothers, is inadequate [28]. This may be one of the reasons as to why subsequent births were less 
Table 1 Characteristics of the study population in India, 2015-16 NFHS

\begin{tabular}{|c|c|c|c|c|c|c|c|c|c|c|c|c|}
\hline & \multicolumn{2}{|c|}{$\begin{array}{l}\text { North } \\
(n=2731)\end{array}$} & \multicolumn{2}{|c|}{$\begin{array}{l}\text { South } \\
(n=3641)\end{array}$} & \multicolumn{2}{|c|}{$\begin{array}{l}\text { East } \\
(n=5177)\end{array}$} & \multicolumn{2}{|c|}{$\begin{array}{l}\text { West } \\
(n=2572)\end{array}$} & \multicolumn{2}{|c|}{$\begin{array}{l}\text { Central } \\
(n=6425)\end{array}$} & \multicolumn{2}{|c|}{$\begin{array}{l}\text { North Eastern } \\
(n=806)\end{array}$} \\
\hline & $\bar{n}$ & $\%$ & $\bar{n}$ & $\%$ & $\overline{\mathrm{n}}$ & $\%$ & $\bar{n}$ & $\%$ & $\bar{n}$ & $\%$ & $\mathrm{n}$ & $\%$ \\
\hline \multicolumn{13}{|l|}{ Child characteristics } \\
\hline \multicolumn{13}{|l|}{ Sex of baby } \\
\hline Male & 1443 & 52.8 & 1880 & 51.7 & 2740 & 52.9 & 1292 & 50.2 & 3190 & 51.4 & 399 & 49.5 \\
\hline Female & 1288 & 47.2 & 1761 & 48.4 & 2436 & 47.1 & 1280 & 49.8 & 3015 & 48.6 & 407 & 50.6 \\
\hline \multicolumn{13}{|l|}{ Age of child (months) } \\
\hline $0-2.9$ & 1108 & 40.6 & 1467 & 40.3 & 2117 & 40.9 & 1054 & 41.0 & 2681 & 43.0 & 351 & 43.5 \\
\hline $3-5.9$ & 1623 & 59.4 & 2174 & 59.7 & 3060 & 59.1 & 1518 & 59.0 & 3525 & 57.0 & 455 & 56.5 \\
\hline \multicolumn{13}{|l|}{ Birth order } \\
\hline First-born & 1130 & 41.4 & 1606 & 4.1 & 1901 & 36.7 & 1074 & 41.8 & 2113 & 34.1 & 323 & 40.1 \\
\hline 2nd-4th & 1428 & 52.3 & 1994 & 54.7 & 2863 & 55.3 & 1438 & 55.9 & 3506 & 56.5 & 420 & 52.1 \\
\hline 5 or more & 173 & 6.3 & 41.0 & 1.1 & 413 & 8.0 & 60 & 2.3 & 587 & 9.5 & 63 & 7.8 \\
\hline \multicolumn{13}{|l|}{ Perceived size of baby } \\
\hline Small & 312 & 11.6 & 349 & 9.7 & 670 & 13.1 & 321 & 12.5 & 928 & 15.1 & 116 & 15.6 \\
\hline Average & 2007 & 74.5 & 2235 & 61.9 & 3303 & 64.5 & 1670 & 65.3 & 4411 & 71.9 & 483 & 64.6 \\
\hline Large & 374 & 13.9 & 1025 & 28.4 & 1145 & 22.4 & 568 & 22.2 & 797 & 13.0 & 148 & 19.8 \\
\hline \multicolumn{13}{|l|}{ Preceding birth interval } \\
\hline No previous birth & 1139 & 41.7 & 1630 & 44.8 & 1914 & 37.0 & 1081 & 42.0 & 2122 & 34.2 & 323 & 40.1 \\
\hline$<24$ months & 401 & 14.7 & 562 & 15.4 & 751 & 14.5 & 357 & 13.9 & 997 & 16.1 & 70 & 8.7 \\
\hline$>24$ months & 1191 & 43.6 & 1449 & 39.8 & 2511 & 48.5 & 1133 & 44.1 & 3087 & 49.7 & 412 & 51.1 \\
\hline \multicolumn{13}{|l|}{ Maternal characteristics } \\
\hline \multicolumn{13}{|l|}{ Mother's age } \\
\hline $15-24$ years & 154 & 6.1 & 341 & 9.4 & 714 & 13.8 & 243 & 9.4 & 317 & 4.9 & 94 & 11.6 \\
\hline $25-34$ years & 2247 & 89.5 & 3211 & 88.2 & 4209 & 81.3 & 2259 & 87.8 & 5779 & 90.0 & 639 & 79.3 \\
\hline $35-49$ years & 111 & 4.4 & 90 & 2.5 & 253 & 4.9 & 70 & 2.7 & 329 & 5.1 & 73 & 9.1 \\
\hline \multicolumn{13}{|l|}{ Mother's education } \\
\hline No education & 758 & 27.8 & 358 & 9.8 & 1870 & 36.1 & 346 & 13.5 & 1987 & 32.0 & 152 & 18.8 \\
\hline Primary & 363 & 13.3 & 258 & 7.1 & 751 & 14.5 & 293 & 11.4 & 943 & 15.2 & 140 & 17.3 \\
\hline Secondary and higher & 1610 & 58.9 & 3025 & 83.1 & 2555 & 49.4 & 1932 & 75.1 & 3275 & 52.8 & 515 & 63.9 \\
\hline \multicolumn{13}{|l|}{ Mother's religion } \\
\hline Hindu & 2074 & 76.0 & 2965 & 81.4 & 3885 & 75.0 & 2083 & 81.0 & 5209 & 83.9 & 380 & 47.2 \\
\hline Muslim & 385 & 14.1 & 475 & 13.1 & 1098 & 21.2 & 342 & 13.3 & 959 & 15.5 & 269 & 33.4 \\
\hline Christianity and others & 272 & 10.0 & 201 & 5.5 & 194 & 3.8 & 147 & 5.7 & 38 & 0.6 & 156 & 19.4 \\
\hline \multicolumn{13}{|l|}{ Type of caste or tribe } \\
\hline Scheduled caste & 718 & 26.3 & 841 & 23.1 & 1139 & 22.0 & 355 & 13.8 & 1408 & 22.7 & 67 & 8.3 \\
\hline Scheduled tribe & 266 & 9.7 & 235 & 6.4 & 611 & 11.8 & 430 & 16.7 & 673 & 10.8 & 215 & 26.6 \\
\hline Other backward class & 983 & 36.0 & 20 & 55.5 & 2179 & 42.1 & 836 & 32.5 & 3065 & 49.4 & 167 & 20.7 \\
\hline Others & 764 & 28.0 & 20 & 15.0 & 1248 & 24.1 & 951 & 37.0 & 1060 & 17.1 & 357 & 44.4 \\
\hline \multicolumn{13}{|l|}{ Family/household characteristics } \\
\hline \multicolumn{13}{|l|}{ Marital status } \\
\hline Currently married & 2721 & 99.7 & 3637 & 99.9 & 5153 & 99.7 & 2555 & 99.4 & 6172 & 99.5 & 799 & 99.3 \\
\hline Formerly married (divorced/separated/ widowed) & 7 & 0.3 & 4 & 0.1 & 16 & 0.3 & 14 & 0.6 & 29 & 0.5 & 5 & 0.7 \\
\hline
\end{tabular}


Table 1 Characteristics of the study population in India, 2015-16 NFHS (Continued)

\begin{tabular}{|c|c|c|c|c|c|c|c|c|c|c|c|c|}
\hline & \multicolumn{2}{|c|}{$\begin{array}{l}\text { North } \\
(n=2731)\end{array}$} & \multicolumn{2}{|c|}{$\begin{array}{l}\text { South } \\
(n=3641)\end{array}$} & \multicolumn{2}{|c|}{$\begin{array}{l}\text { East } \\
(n=5177)\end{array}$} & \multicolumn{2}{|c|}{$\begin{array}{l}\text { West } \\
(n=2572)\end{array}$} & \multicolumn{2}{|c|}{$\begin{array}{l}\text { Central } \\
(n=6425)\end{array}$} & \multicolumn{2}{|c|}{$\begin{array}{l}\text { North Eastern } \\
(n=806)\end{array}$} \\
\hline & $n$ & $\%$ & $n$ & $\%$ & $n$ & $\%$ & $n$ & $\%$ & $\mathrm{n}$ & $\%$ & $n$ & $\%$ \\
\hline Poor & 755 & 27.7 & 798 & 21.9 & 3826 & 73.9 & 732 & 28.5 & 3391 & 54.7 & 524 & 65.0 \\
\hline Middle & 498 & 18.2 & 1025 & 28.1 & 746 & 14.4 & 587 & 22.8 & 1150 & 18.5 & 157 & 19.5 \\
\hline Rich & 1478 & 54.1 & 1819 & 50.0 & 605 & 11.7 & 1253 & 48.7 & 1664 & 26.8 & 125 & 15.5 \\
\hline \multicolumn{13}{|l|}{ Health service characteristics } \\
\hline \multicolumn{13}{|l|}{ Antenatal clinic visits } \\
\hline None & 308 & 11.3 & 263 & 7.2 & 1364 & 26.4 & 243 & 9.5 & 1037 & 16.7 & 112 & 13.9 \\
\hline $1-3$ & 1006 & 36.8 & 455 & 12.5 & 1821 & 35.2 & 448 & 17.4 & 2988 & 48.2 & 304 & 37.7 \\
\hline $4+$ & 1418 & 51.9 & 2923 & 80.3 & 1992 & 38.5 & 1880 & 73.1 & 2181 & 35.1 & 390 & 48.4 \\
\hline \multicolumn{13}{|l|}{ Place of delivery } \\
\hline Home & 300 & 11.0 & 109 & 3.0 & 1401 & 27.1 & 185 & 7.2 & 1412 & 22.8 & 239 & 29.6 \\
\hline Health facility & 2431 & 89.0 & 3532 & 97.0 & 3775 & 72.9 & 2387 & 92.8 & 4793 & 77.2 & 567 & 70.4 \\
\hline \multicolumn{13}{|l|}{ Type of delivery assistance } \\
\hline Health professional & 2239 & 82.3 & 3244 & 89.2 & 3154 & 61.4 & 2060 & 80.6 & 3645 & 59.1 & 556 & 70.6 \\
\hline Traditional birth attendants & 182 & 6.7 & 78 & 2.2 & 832 & 16.2 & 84 & 3.3 & 760 & 12.3 & 83 & 10.5 \\
\hline Other untrained personnel & 300 & 11.0 & 316 & 8.7 & 1150 & 22.4 & 413 & 16.2 & 1765 & 28.6 & 149 & 18.9 \\
\hline \multicolumn{13}{|l|}{ Mode of delivery } \\
\hline Vaginal & 2291 & 83.9 & 2121 & 58.3 & 4497 & 86.9 & 1984 & 77.2 & 5488 & 88.4 & 667 & 82.8 \\
\hline Caesarean & 440 & 16.1 & 1520 & 41.8 & 680 & 13.1 & 588 & 22.9 & 718 & 11.6 & 138 & 17.2 \\
\hline \multicolumn{13}{|l|}{ Community-level factor } \\
\hline \multicolumn{13}{|l|}{ Residence } \\
\hline Urban & 878 & 32.2 & 1388 & 38.1 & 760 & 14.7 & 10,651 & 41.3 & 1350 & 21.8 & 111 & 13.7 \\
\hline Rural & 1853 & 67.8 & 2253 & 61.9 & 4417 & 85.3 & 1510 & 58.7 & 4856 & 78.3 & 695 & 86.3 \\
\hline
\end{tabular}

likely to exclusively receive only breast milk in the first six months of life. Additionally, a study from India reported that undernutrition was associated with first-born babies compared to subsequent births, and the burden increases further with increasing birth order [36], highlighting the issue of a lack of coordinated action for IYCF programmes in the country.

Improved maternal education is one of the single most important measures to improve not only child nutrition and survival but also maternal health and household social-emotional interaction [37, 38]. Our study suggests that higher maternal education was associated with nonEBF in the Southern region, but the opposite association was observed in the Central region of India, where higher maternal education was associated with EBF. Additionally, mothers from more wealthy households were less likely to engage in EBF compared to those from poorer households in Central India. Higher maternal education is linked with increased opportunity for professional employment and subsequently improved household income [39]. Mothers who are employed are less likely to engage in EBF, especially when they work in environments that provide limited opportunities for optimal breastfeeding [39, 40]. In comparison to Central India, the Southern region has a higher literacy rate [10], better economic indices and opportunities for employment [41]. These factors may account for the observed differences in EBF among mothers from those regions.

Notably, the Government of India has recently taken actions to improve maternal and child health, including EBF. These efforts include the introduction of various schemes (e.g. Pradhan Mantri Matru Vandana Yojana, PMMVY) [42] and recent amendments to the Maternity Benefit Act, 1961 [henceforth, Maternity Benefit (Amendment) Act, 2017]. The amendment protects women's employment, and women's and children's well-being during maternity, with paid absence and related benefits. It also increased the maternity leave from 12 weeks to 26 weeks and makes the provision of crèche facility mandatory for every company employing more than 50 employees, with the specific target of improving the EBF [43].

Furthermore, improving EBF participation in India would also require increased girl child education as articulated in the Sustainable Development Goals [44] and the full implementation of the India World Breastfeeding Trends Initiative (WBTi) recommendations [28]. 

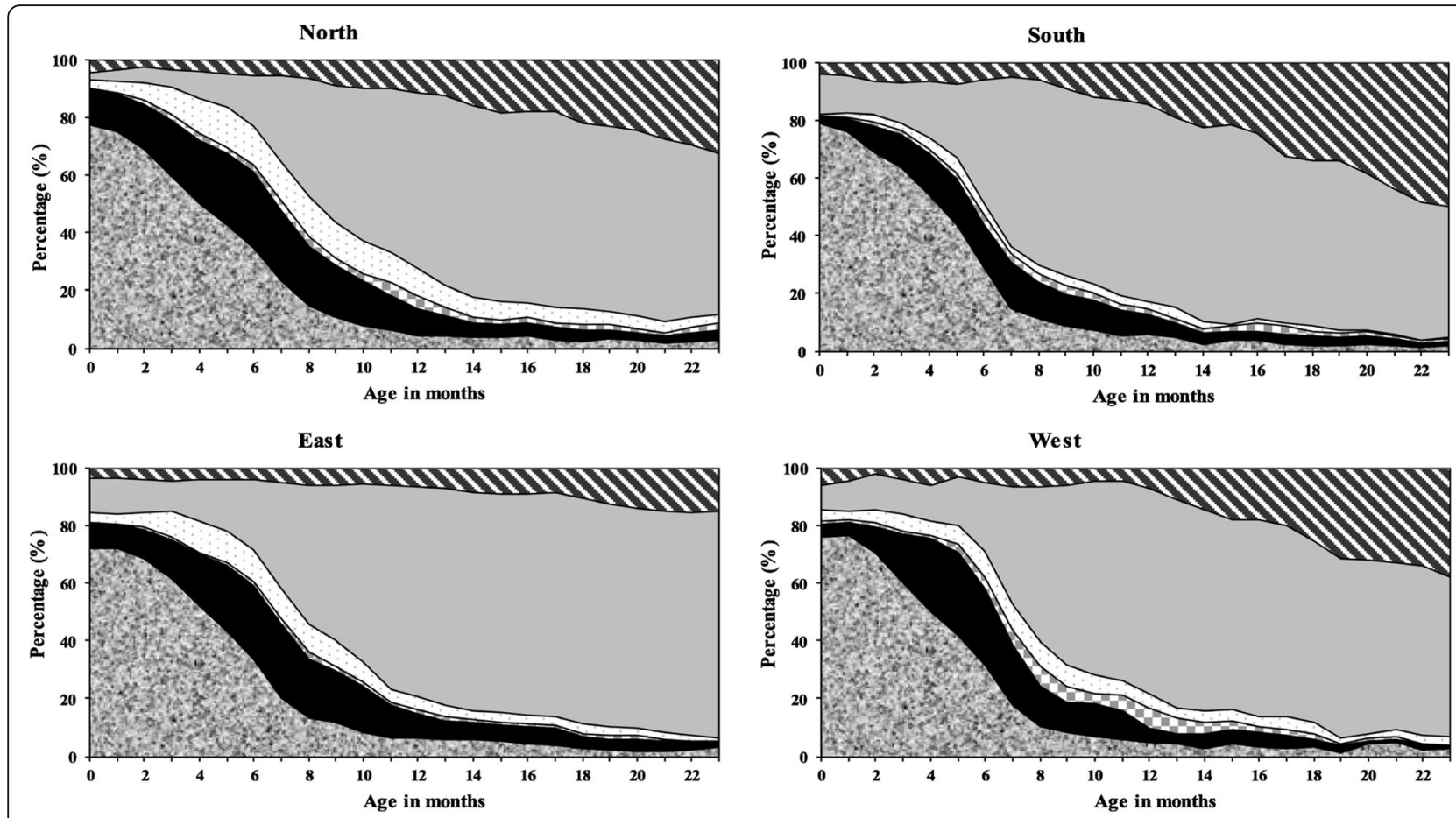

Central
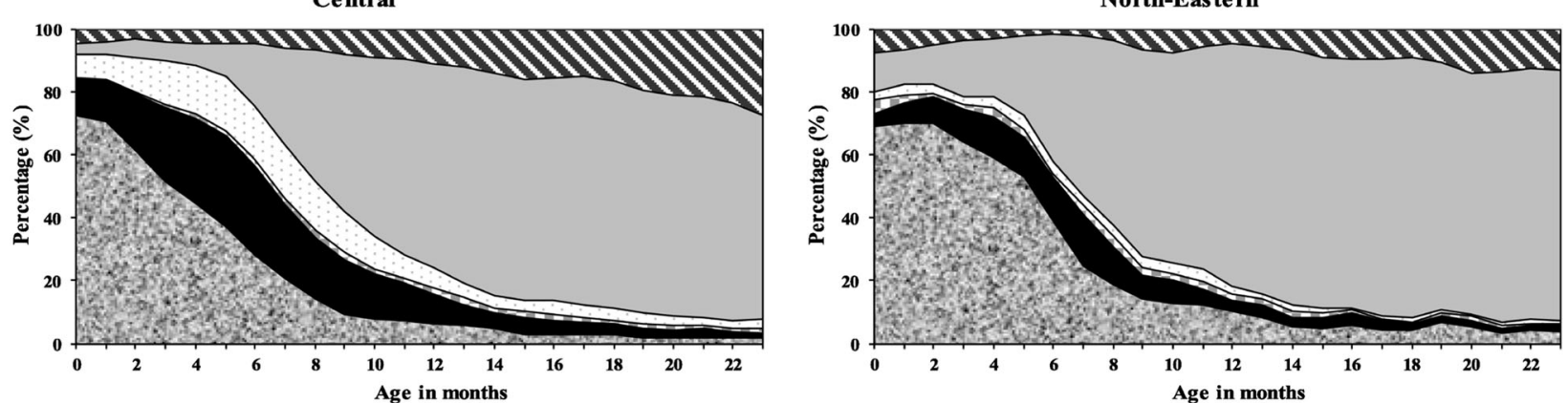

Q Exclusive BF

田 BF+Liquids/Juice

$\square \mathrm{BF}+$ Complementary feeds
- BF+Water

$\square \mathrm{BF}+$ Other milk

\section{$\mathbf{N}$ No BF}

Fig. 1 Regional distribution of exclusive breastfeeding (BF) and other infant and young child feeding practices by child age in India, 2015-2016 (NFHS-4)

These include the establishment of the Baby Friendly Hospital Initiative (BFHI) centres and the provision of information support for breastfeeding, as well as strengthening monitoring and evaluation systems. In 2016, the Government of India introduced the Mothers Absolute Affection (MAA) programme, with a focus to intensify efforts towards the promotion, protection and support of optimal breastfeeding across regions of the country. The programme aims to i) generate breastfeeding activities and provide an enabling environment for pregnant and lactating mothers, family member and community; ii) intensify and support breastfeeding- related activities in public health facilities through facility- and community-based healthcare workers; and iii) recognise and provide additional support to healthcare facilities with improved breastfeeding outcomes [45]. While this initiative provides a good opportunity for Indian mothers to increase breastfeeding for their children, efforts such as revitalising the country's BFHI remain a key priority [28].

Consistent with past reports [25, 26, 32], our study indicated that frequent $(\geq 4)$ antenatal visits were associated with EBF among mothers in Northern India. The WHO recommends that pregnant women should attend at least 


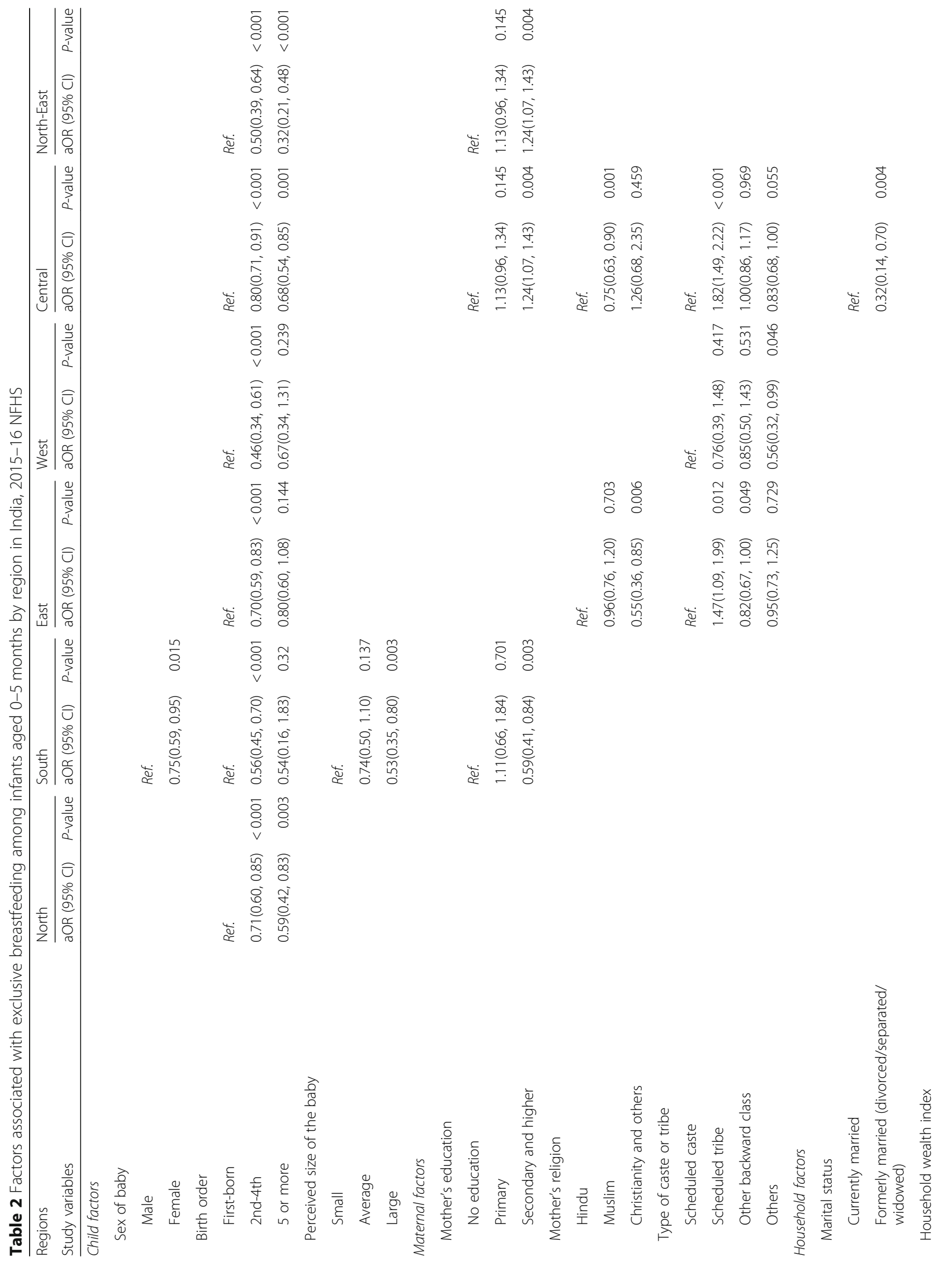


Ogbo et al. International Breastfeeding Journal

(2019) 14:20

Page 9 of 12

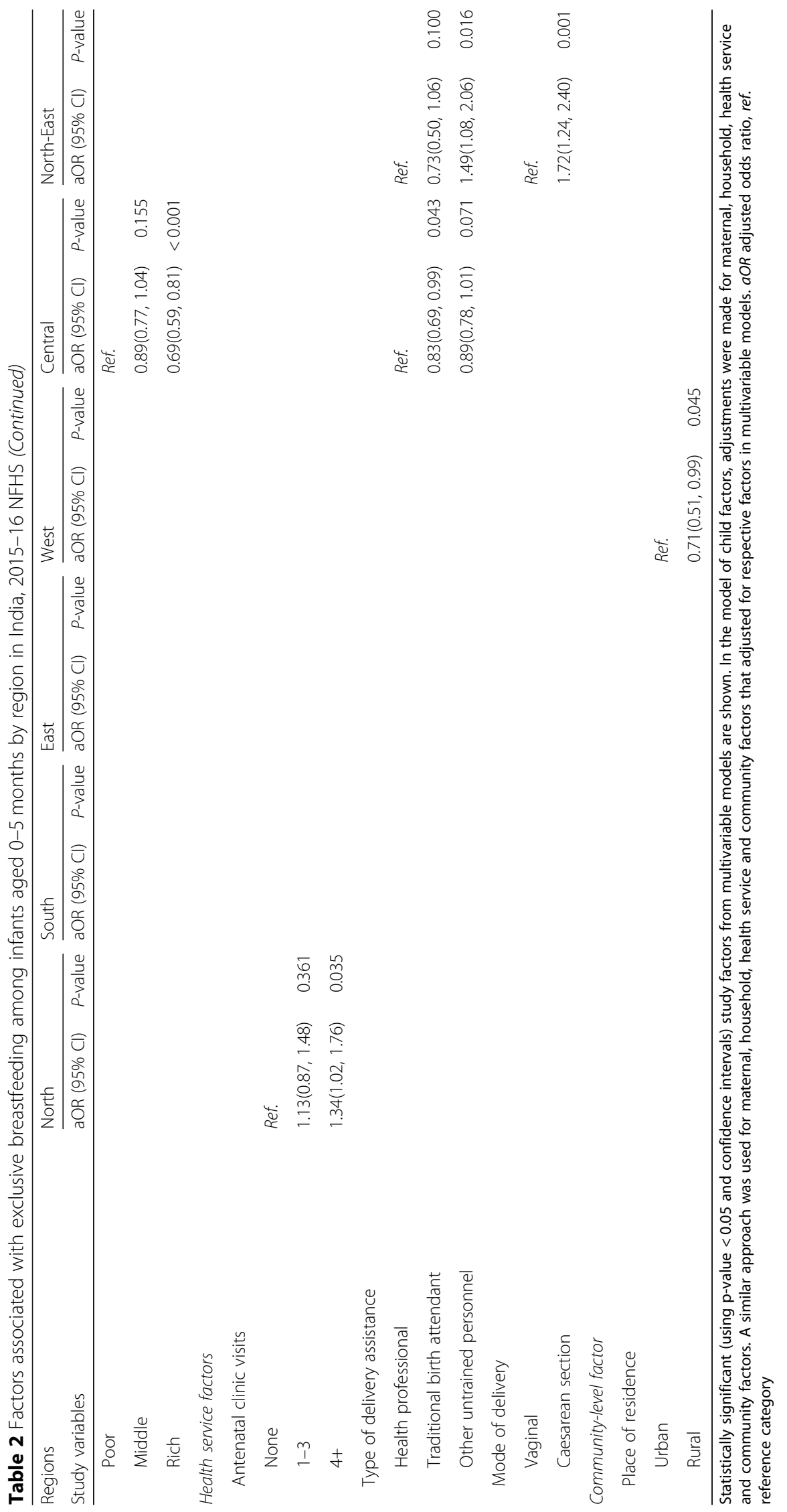


four antenatal visits to create opportunities for risk identification; prevention and management of pregnancy-related and/or comorbidities; and health education and health promotion, including the provision of EBF information [46]. More recently, the Government of India has introduced various maternal health schemes (e.g. Pradhan Mantri Surakshit Matritva Abhiyan, PMSMA; PMMVY and LaQshya programmes). These interventions aim to improve antenatal care uptake and ensure quality care during pregnancy, birthing and the immediate post-partum period for women and their newborn [42, 47]. While these initiatives are needed and well-deserved to improve not only maternal health but also newborn care (including EBF), the establishment and integration of IYCF programme interventions with the programmes are also critical to improving EBF and subsequent child survival in India.

In the present study, other significant factors associated with non-EBF included residence in rural areas in Western India; female gender and perceived large babies in Southern India; practising Christianity and other religious backgrounds in Eastern India and being of Muslim background in North-Eastern regions. In contrast, belonging to the 'Scheduled tribe' was associated with EBF in East and North-East regions of India, while mothers from 'Other backward class' had lower odds of EBF in Eastern India. Evidence from many developing countries [11, 32, 48-50] has shown that the determinants of EBF practice are multifaceted, and therefore, interventions aimed at increasing EBF rates would require a multipronged approach that considers the specific environment in which mothers raise their children. The India WBTi recommended the allocation of special funds for IYCF policy and programmes implementation as a major strategy for improving IYCF in the country [28]. Importantly, the Indian government is already dedicating funds to promote IYCF as part of various national programmes, including the Home-Based Newborn Care, the Home Based Young Child Care and the Integrated Child Development Services [42, 47]. However, whether these interventions are targeted at high-risk populations to increase EBF participation among Indian women remains unclear. Future studies that evaluate the positive impacts of these policy interventions in the context of EBF may be warranted to inform refinement of future programmes.

\section{Study limitations and strengths}

The study has several methodological limitations that should be considered when interpreting the results. First, we used cross-sectional data, and this makes the articulation of a clear temporal association between the study factors and EBF difficult. Second, the DHS data used for this study were collected through self-report, and this is a source of recall bias which may have either underestimated or overestimated the relationship between the study factors and EBF. Finally, we were unable to measure all possible variables and/or contextual factors that could potentially affect EBF in India, including partner support, a cultural belief system for infant feeding and health professional's knowledge of EBF. The lack of assessment of these unmeasured factors may have affected our results. Despite these methodological limitations, the study has strengths. First, we used data that had high response rates (from 94.0 to $99.6 \%$ across the states of India) suggesting that the potential effect of selection bias is unlikely to be present in our study findings. Second, the India DHS data were collected by skilled personnel using standardised questionnaires which ensured that the data collected were consistent across the states and territories of India. Lastly, our study provided evidence on important modifiable factors associated with EBF in the world's second largest populations to help nutrition experts in the country advocate for effective policies and intervention services to improve EBF in India.

\section{Conclusion}

The present study suggests that there were considerable variations in the prevalence of EBF and other IYCF practices across the regions of India. Southern India had the highest EBF prevalence, while the North-East had the lowest prevalence. The determinants of EBF also varied across regional lines, where higher birth order was the only common factor associated with non-EBF in all regions. Key modifiable determinants of non-EBF included higher maternal education in the South and belonging to rich households in Central India. Efforts to improve EBF in India would require a multipronged approach, where political will and dedicated funds for those public health actions and the establishment of IYCF policy and programmes interventions remain core priorities.

\section{Additional file}

Additional file 1: Univariate analyses of factors associated with exclusive breastfeeding among infants aged 0-5 months by region in India, 2015-16 NFHS (PDF $212 \mathrm{~kb})$

\section{Abbreviations \\ DHS: Demographic and health survey; EBF: Exclusive breastfeeding; IIPS: International Institute for Population Sciences; NFHS: National Family and Health Survey}

\section{Acknowledgements}

The authors are grateful to Measure DHS, ICF International, Rockville, Maryland, USA for providing the data for the analysis.

\section{Funding}

This study received no specific grant from any funding agency in public, commercial or not-for-profit sectors.

Availability of data and materials

The study was based on the 2015-16 India Demographic and Health Survey data, with some restriction imposed by the DHS Program. Approval to use 
these data was sought from Measure DHS/ICF International, and permission was granted for this use. The data are available to apply for online at https:// dhsprogram.com/data/available-datasets.cfm. Contact information for data access: The DHS Program Office, ICF, 530 Gaither Road, Suite 500, Rockville, MD 20850. Tel: + 1301 407-6500; Fax: + 1301 407-6501; email: info@dhsprogram.com

\section{Author's contribution}

FAO conceived the study idea, contributed to the data analyses and results interpretation, drafted the original manuscript, provided general supervision and critically revised the final manuscript as submitted. MVD contributed to the data analyses, compiled the results and critically revised the manuscript as submitted. AOA, BOO, JO, ULO, PRG and AP contributed to the data interpretation and critical revision of the manuscript as submitted. KEA contributed to data analyses and subsequent interpretation and critically revised the manuscript as submitted. All authors read and approved the final manuscript as submitted.

\section{Ethics approval and consent to participate}

The Ethics Review Board at the International Institute for Population Sciences, Mumbai, India granted Measure DHS/ICF International ethical approvals before the surveys were conducted, with written informed consent obtained from participants during the surveys. The questionnaires used for the survey were reviewed and approved by ICF International Institutional Review Board (IRB) to ensure they met the United States Department of Health and Human Services regulations for the protection of human participants, as well as the host country's IRB, to ensure compliance with national laws. Approval was sought from Measure DHS and permission was granted for this use.

\section{Consent for publication}

This article contains no personal data in any form.

\section{Competing interests}

The authors declare that they have no competing interests.

\section{Publisher's Note}

Springer Nature remains neutral with regard to jurisdictional claims in published maps and institutional affiliations.

\section{Author details}

${ }^{1}$ Translational Health Research Institute (THRI), School of Medicine, Western Sydney University, Campbelltown Campus, Locked Bag 1797, Penrith, NSW 2571, Australia. ${ }^{2}$ Prescot Specialist Medical Centre, Welfare Quarters, Makurdi, Benue State, Nigeria. ${ }^{3}$ Centre for Healthy Start Initiative, 286A Corporation Drive, Dolphin Estate, Ikoyi, Lagos, Nigeria. ${ }^{4}$ School of Medicine | Diabetes Obesity and Metabolism Translational Research Unit (DOMTRU), Macarthur Clinical School, Parkside Crescent, Campbelltown, NSW 2560, Australia. ${ }^{5}$ School of Science and Health, Western Sydney University, Campbelltown Campus, Locked Bag 1797, Penrith, NSW 2571, Australia.

\section{Received: 6 September 2018 Accepted: 26 April 2019} Published online: 16 May 2019

\section{References}

1. Adu-Afarwuah S, Lartey A, Dewey KG. Meeting nutritional needs in the first 1000 days: a place for small-quantity lipid-based nutrient supplements. Annals of the New York Academy of Sciences. 2017;1392(1):18-29.

2. Ogbo FA, Page A, Idoko J, Claudio F, Agho KE. Diarrhoea and suboptimal feeding practices in Nigeria: evidence from the national household surveys. Paediatr Perinat Epidemiol. 2016;30:346-55.

3. Ogbo FA, Agho K, Ogeleka P, Woolfenden S, Page A, Eastwood J. Infant feeding practices and diarrhoea in sub-Saharan African countries with high diarrhoea mortality. PLoS One. 2017;12(2):e0171792.

4. Victora CG, Bahl R, Barros AJ, França GV, Horton S, Krasevec J, et al. Breastfeeding in the 21st century: epidemiology, mechanisms, and lifelong effect. Lancet. 2016;387(10017):475-90.

5. World health organization. Indicators for assessing infant and young child feeding practices. Geneva, Switzerland; 2008.
6. Ogbo FA, Nguyen $\mathrm{H}$, Naz S, Agho KE, Page A. The association between infant and young child feeding practices and diarrhoea in Tanzanian children. Tropical Medicine and Health. 2018;46:2.

7. Haidong W, Amanuel AA, Kalkidan HA, Cristiana A, Kaja MA, Foad A-A, et al. Global, regional, and national under-5 mortality, adult mortality, age-specific mortality, and life expectancy, 1970-2016: a systematic analysis for the Global Burden of Disease Study 2016. The Lancet. 2017;390:1084-150.

8. Gakidou E, Afshin A, Abajobir AA, Abate KH, Abbafati C, Abbas MK, et al. Global, regional, and national comparative risk assessment of 84 behavioural, environmental and occupational, and metabolic risks or clusters of risks, 1990-2016: a systematic analysis for the global burden of disease study 2016. Lancet. 2017;390:1345-422.

9. Forouzanfar MH, Afshin A, Alexander LT, Aasvang GM, Bjertness E, Htet AS, et al. Global, regional, and national comparative risk assessment of 79 behavioural, environmental and occupational, and metabolic risks or clusters of risks, 1990-2015: a systematic analysis for the Global Burden of Disease Study 2015. The Lancet. 2016;388:1659-724.

10. Ministry of Health and Family Welfare, International Institute for Population Sciences (IIPS) and ICF. National Family Health Survey (NFHS-4), 2015-16. Mumbai, India: Ministry of Health and Family Welfare, 2018.

11. Menon P, Nguyen PH, Mani S, Kohli N, Avula R, Tran LM. Trends in nutrition outcomes, determinants, and interventions in India (2006-2016). New Delhi: International Food Policy Research Institute; 2017.

12. Velusamy V, Premkumar PS, Kang G. Exclusive breastfeeding practices among mothers in urban slum settlements: pooled analysis from three prospective birth cohort studies in South India. Int Breastfeed J. 2017;12:35.

13. Bentley A, Das S, Alcock G, More NS, Pantvaidya S, Osrin D. Malnutrition and infant and young child feeding in informal settlements in Mumbai, India: findings from a census. Food Science and Nutrition. 2015;3(3):257.

14. Chandhiok N, Singh KJ, Sahu D, Singh L, Pandey A. Changes in exclusive breastfeeding practices and its determinants in India, 1992-2006: analysis of national survey data. Int Breastfeed J. 2015:10:34

15. Luke N, Munshi K. Women as agents of change: female income and mobility in India. J Dev Econ. 2011;94(1):1-17.

16. Patel R, Parmentier MJC. The persistence of traditional gender roles in the information technology sector: a study of female engineers in India. Information Technologies \& International Development. 2005;2(3):29-46.

17. Bhattacharyya R. Examining the changing status and role of middle class Assamese women: lessons from the lives of University students. Online: University of Newcastle; 2009.

18. International Institute for Population Sciences (IIPS), ICF. National Family Health Survey (NFHS-4), India. Mumbai, India IIPS, 2017

19. Agho KE, Ezeh OK, Ogbo FA, Enoma Al, Raynes-Greenow C. Factors associated with inadequate receipt of components and use of antenatal care services in Nigeria: a population-based study. Int Health. 2018;10(3):172-81.

20. International Institute for Population Sciences (IIPS), ICF. National Family Health Survey (NFHS-4), West Bengal. Mumbai, India IIPS, 2017.

21. International Institute for Population Sciences (IIPS), ICF. National Family Health Survey (NFHS-4), Andhra Pradesh. Mumbai, India IIPS., 2018.

22. International Institute for Population Sciences (IIPS), ICF. National Family Health Survey (NFHS-4), Bihar. Mumbai, India IIPS, 2017.

23. Government of India-Ministry of Home Affairs. Zonal Council Online: Government of India; 2018 [cited 2018 June 30]. Available from: https:// mha.gov.in/zonal-council

24. Ghatowar SPS. The North-Eastern Council (Amendment) Bill. In: Ministry of Development of NorthEastern Region, MoS in the Ministry of Parliamentary Affairs, editors. New Dehli 2013.

25. Ogbo FA, Eastwood J, Page A, Efe-Aluta O, Anago-Amanze C, Kadiri EA, et al. The impact of sociodemographic and health-service factors on breastfeeding in sub-Saharan African countries with high diarrhoea mortality. Public Health Nutr. 2017;20(17):3109-19.

26. Ogbo FA, Agho KE, Page A. Determinants of suboptimal breastfeeding practices in Nigeria: evidence from the 2008 demographic and health survey. BMC Public Health. 2015;15:259.

27. Black RE, Victora CG, Walker SP, Bhutta ZA, Christian P, de Onis M, et al. Maternal and child undernutrition and overweight in low-income and middle-income countries. Lancet. 2013;382(9890):427-51.

28. Breastfeeding Promotion Network of India (BPNI)International baby food action network (IBFAN) Asia. Arrested development: 5th report of assessment of India's policy and Programmes on infant and young child feeding Delhi. In: World breastfeeding trends initiative (WBTi). India; 2018. 
29. Aruldas K, Khan M, Hazra A. Increasing early and exclusive breastfeeding in rural Uttar Pradesh. J Fam Welf. 2010;56 (special issue 2010:43-50.

30. UNICEF - India. Early and Exclusive breastfeeding Online: Unicef; 2018 [cited 2018 August 24]. Available from: http://unicef.in/AddNewPage/PreView/21

31. Ogbo FA, Page A, Agho KE, Claudio F. Determinants of trends in breastfeeding indicators in Nigeria, 1999-2013. Public Health Nutr. 2015;18:3287-99.

32. Victor R, Baines SK, Agho KE, Dibley MJ. Determinants of breastfeeding indicators among children less than 24 months of age in Tanzania: a secondary analysis of the 2010 Tanzania demographic and health survey. BMJ Open. 2013;3(1):e001529.

33. Perera PJ, Ranathunga N, Fernando MP, Sampath W, Samaranayake GB. Actual exclusive breastfeeding rates and determinants among a cohort of children living in Gampaha district Sri Lanka: a prospective observational study. Int Breastfeed J. 2012;7:21.

34. Ministry of Health -Tanzania. The world breastfeeding trends initiative (WBTi) - Tanzania. Tanzania: Ministry of Health, 2015.

35. UNICEF. Consolidated report of six-country review of breastfeeding programmes. New York: UNICEF; 2010.

36. Kumar A, Singh V. A study of exclusive breastfeeding and its impact on nutritional status of child in EAG states. Journal of Statistics Applications \& Probability. 2015:4(3):435.

37. Carneiro P, Meghir C, Parey M. Maternal education, home environments, and the development of children and adolescents. J Eur Econ Assoc. 2013; 11(Suppl 1):123-60.

38. Matsumura M, Gubhaju B. Women's status, household structure and the utilization of maternal health services in Nepal: even primary-leve1 education can significantly increase the chances of a woman using maternal health care from a modem health facility. Asia-Pac Popul J. 2001; 16(1):23-44

39. Skafida V. Juggling work and motherhood: the impact of employment and maternity leave on breastfeeding duration: a survival analysis on growing up in Scotland data. Matern Child Health J. 2012:16(2):519-27.

40. Ogbo FA, Eastwood J, Page A, Arora A, McKenzie A, Jalaludin B, et al. Prevalence and determinants of cessation of exclusive breastfeeding in the early postnatal period in Sydney, Australia. Int Breastfeed J. 2017;12:16.

41. Krishna KL. Patterns and determinants of economic growth in Indian statesNew Delhi: Inidian Council for Research on international economic relations. Contract. 2004:144.

42. Ministry of Women and Child Development. Pradhan Mantri Matru Vandana Yojana Online: Ministry of Women and Child Development; 2019 [cited 2019 January 20]. Available from: http://www.wcd.nic.in/schemes/pradhanmantri-matru-vandana-yojana

43. D'Cunha J. India's bold maternity benefit act can become a game changer if it addresses current limitations. Econ Polit Wkly. 2018;53(31):1-9.

44. United Nations. Sustainable development goals Online: United Nations; 2016 [cited 201828 July ]. Available from: http://www.un.org/ sustainabledevelopment/sustainable-development-goals/.

45. Monalisha S. Exclusive breastfeeding - mothers absolute affection. Acta Scientific Medical Sciences. 2018;2(8):1-2.

46. World Health Organization. WHO recommendations on antenatal care for a positive pregnancy experience. Geneva: World Health Organization; 2016.

47. Government of India. The Pradhan Mantri Surakshit Matritva Abhiyan. In: Ministry of Health and Family Welfare - maternal health division, editor. New Delhi: Ministry of Health and Family Welfare; 2016

48. Ogbo FA, Page A, Idoko J, Claudio F, Agho KE. Have policy responses in Nigeria resulted in improvements in infant and young child feeding practices in Nigeria? Int Breastfeed J. 2017;12:9.

49. Seid MA, Yesuf ME, Koye DN. Prevalence of exclusive breastfeeding practices and associated factors among mothers in Bahir Dar city, Northwest Ethiopia: a community based cross-sectional study. Int Breastfeed J. 2013;8:14.

50. Hazir T, Akram D-S, Nisar YB, Kazmi N, Agho KE, Abbasi S, et al. Determinants of suboptimal breast-feeding practices in Pakistan. Public Health Nutr. 2013;16(04):659-72.

Ready to submit your research? Choose BMC and benefit from:

- fast, convenient online submission

- thorough peer review by experienced researchers in your field

- rapid publication on acceptance

- support for research data, including large and complex data types

- gold Open Access which fosters wider collaboration and increased citations

- maximum visibility for your research: over $100 \mathrm{M}$ website views per year

At BMC, research is always in progress.

Learn more biomedcentral.com/submissions 